\title{
Pre-mRNA Processing Is Partially Impaired in Satellite Cell Nuclei from Aged Muscles
}

\author{
Manuela Malatesta, ${ }^{1}$ Federica Perdoni, ${ }^{2}$ Sylviane Muller, ${ }^{3}$ Carlo Pellicciari, ${ }^{2}$ \\ and Carlo Zancanaro ${ }^{1}$
${ }^{1}$ Dipartimento di Scienze Morfologico-Biomediche, Sezione di Anatomia e Istologia, University of Verona, Strada Le Grazie 8, 37134 Verona, Italy
${ }^{2}$ Laboratorio di Biologia Cellulare, Dipartimento di Biologia Animale, University of Pavia, Via Ferrata 9a, 27100 Pavia, Italy
${ }^{3}$ CNRS, Institut de Biologie Moléculaire et Cellulaire, Immunologie et Chimie Thérapeutiques, 15 rue R. Descartes, 67084 Strasbourg Cedex, France

Correspondence should be addressed to Manuela Malatesta, manuela.malatesta@univr.it

Received 30 October 2009; Accepted 3 February 2010

Academic Editor: Guy M. Benian

Copyright (C) 2010 Manuela Malatesta et al. This is an open access article distributed under the Creative Commons Attribution License, which permits unrestricted use, distribution, and reproduction in any medium, provided the original work is properly cited.

Satellite cells are responsible for the capacity of mature mammalian skeletal muscles to repair and maintain mass. During aging, skeletal muscle mass as well as the muscle strength and endurance progressively decrease, leading to a condition termed sarcopenia. The causes of sarcopenia are manifold and remain to be completely elucidated. One of them could be the remarkable decline in the efficiency of muscle regeneration; this has been associated with decreasing amounts of satellite cells, but also to alterations in their activation, proliferation, and/or differentiation. In this study, we investigated the satellite cell nuclei of biceps and quadriceps muscles from adult and old rats; morphometry and immunocytochemistry at light and electron microscopy have been combined to assess the organization of the nuclear RNP structural constituents involved in different steps of mRNA formation. We demonstrated that in satellite cells the RNA pathways undergo alterations during aging, possibly hampering their responsiveness to muscle damage.

\section{Introduction}

The capacity of mature mammalian skeletal muscles to repair and maintain mass is due to the presence of undifferentiated mononuclear myogenic precursor cells, that is, the satellite cells, located at the periphery of myofiber, between the sarcolemma and the surrounding basal lamina. Satellite cells remain quiescent until appropriate stimuli (e.g., muscle injury) trigger their re-entry into the cell cycle; they then undergo activation and proliferation, and the daughter cells fuse to form muscle fibers which increase muscle mass. The availability and responsiveness of satellite cells are therefore necessary for efficient muscle regeneration.

During aging, a progressive loss of skeletal muscle mass and a parallel decrease in muscle strength and endurance take place. This condition, termed sarcopenia, has important health-care and socioeconomic implications for humans, since it contributes to frailty, functional loss, dependence, disability, high health care costs, and premature death (the recent review in [1]).

The mechanisms leading to sarcopenia are probably manifold and they still remain to be completely elucidated (review in $[2,3]$ ). One of the possible causes could be the remarkable decline in the efficiency of muscle regeneration; this has been associated with decreasing amounts of satellite cells (e.g., $[4-8]$ ), possibly due to apoptotic cell death $[9,10]$, although this is controversial [11-13]. It has also been suggested that activation, proliferation, and/or differentiation of satellite cells and their progeny may be altered in sarcopenia $[14,15]$.

It is known that aging involves alterations in the pathways of gene expression, which are not necessarily associated with mutations but can imply impairments in pre-mRNA transcription and/or splicing (review in [16]). In particular, it has 
been shown that aging affects intranuclear RNA pathways by altering the organization, composition, and location of the ribonucleoprotein-(RNP-) containing structures [17-21]. These structures are part of the transcription and splicing machinery: perichromatin fibrils (PFs) are the morphological equivalent of hnRNA transcription and cotranscriptional splicing, perichromatin granules (PG), which form by PF coiling, are involved in the storage and the nucleus-tocytoplasm transport of mRNA, while interchromatin granules (IG) represent the storage, assembly, and recycling site for snRNP and non-snRNP splicing factors [22-24].

In a recent study [25], we have analyzed the fine structure of myonuclei as well as the distribution and amount of RNA processing factors in myofibers of biceps brachii and quadriceps femoris from adult and old rats. We thus showed that in myonuclei of aged fibers a decrease in the transcription, processing, and transport rate of pre-mRNA takes place. Both muscles contain a high proportion (about $90 \%$ ) of type II fibers and are therefore largely affected by sarcopenia [26-28].

In the present study, we focused our attention on satellite cells of those same muscles. To determine whether the RNA pathways also undergo alterations in the satellite cells of aging muscles, we combined morphometry and immunocytochemistry at light and electron microscopy and investigated the distribution and content of nuclear RNP structural constituents involved in different steps of mRNA formation.

\section{Materials and Methods}

2.1. Animals. Two adult (9 months of age) and two old ( 28 months of age) male Wistar rats were used. All animals were bred under controlled environmental conditions with a 12hour light/dark cycle and fed ad libitum with a standard commercial chow. The experimental protocols comply with the guidelines of the Italian Ministry of Health as well as with internationally recognized guidelines.

The rats were deeply anesthetized with pentobarbital $(50 \mathrm{mg} / \mathrm{Kg}$ i.p.) and then perfused via the ascending aorta with a brief prewash of $0.09 \% \mathrm{NaCl}$ solution followed by $300 \mathrm{~mL}$ of a fixative solution containing $4 \%(\mathrm{v} / \mathrm{v})$ paraformaldehyde in $0.1 \mathrm{M}$ phosphate buffer, $\mathrm{pH} 7.4$ at $4^{\circ} \mathrm{C}$. Biceps brachii and quadriceps femoris muscles were quickly removed and placed in the same fixation solution for 2 hours at $4^{\circ} \mathrm{C}$.

2.2. Light Microscopy. After fixation, muscle samples were dehydrated with ethanol and embedded in paraffin wax. Seven- $\mu \mathrm{m}$-thick muscle samples were cross-sectioned then submitted to immunohistochemical procedures for identification of satellite cells by using a mouse monoclonal antibody directed against the membrane-bound neural cell adhesion molecule (N-CAM/CD56/Leu-19), which has been demonstrated on satellite cells in normal adult skeletal muscle and represents an established marker [29] (BD Biosciences, San Jose, CA). The primary antibody was then revealed with an Alexa 488 conjugated antibody against mouse IgG (Molecular Probes, Invitrogen, Milan, Italy). The sections were finally counterstained for DNA with $0.1 \mu \mathrm{g} / \mathrm{mL}$ Hoechst 33258 to label the cell nuclei and to detect the occurrence of apoptosis based on chromatin morphology. Observations were made with an Olympus BX51 microscope equipped with a $100 \mathrm{~W}$ mercury lamp under the following conditions: 330 - to 385-nm excitation filter (excf), 400$\mathrm{nm}$ dichroic mirror (dm), and 420-nm barrier filter (bf), for Hoechst 33258; 450- to 480-nm excf, 500-nm dm, and $515 \mathrm{~nm}$ bf for Alexa 488. Micrographs were recorded with an Olympus Camedia C-5050 digital camera and stored on a PC by the Olympus software for processing and printing. Morphometrical evaluations were performed by using the software Image J (NIH, USA).

To estimate the possible decrease in the amount of satellite cells in the muscles, the number of satellite cells was determined over areas of cross-sectioned muscles containing only myofibers and endomysium; using a $40 \times$ objective lens, a total of $880,000 \mu \mathrm{m}^{2}$ were considered per each muscle, and the density of satellite cells was expressed as satellite cells $/ 1000 \mu \mathrm{m}^{2}$ of muscle area. The percentage of apoptotic nuclei was evaluated in the counted satellite cells.

The percentage of apoptotic nuclei was also evaluated on myofibres, on a total of 25 microscope fields, using an $\times 20$ objective lens (at least 2000 myonuclei per muscle sample were counted).

2.3. Transmission Electron Microscopy. After fixation, muscle samples were washed in Sörensen buffer and subsequently in phosphate buffered saline (PBS), kept in $0.5 \mathrm{M} \mathrm{NH}_{4} \mathrm{Cl}$ in PBS for 45 minutes to block free aldehydes, dehydrated with ethanol, and embedded in LR White resin polymerized under U.V. light. This fixation procedure is optimal to allow antigen detection at electron microscopy, although the ultrastructural morphology of especially the cellular membranes cannot be perfectly preserved.

Ultrathin sections were collected on Formvar-carbon coated nickel grids and used for morphometrical and immunocytochemical analyses.

Morphometrical evaluations (x11,000) were made on twelve satellite cell nuclei per muscle by using a computerized image analysis system (AnalySIS Image processing, Soft Imaging System GmbH, Muenster, Germany). The following parameters were considered: area of nuclei and nucleoli, percentage of nuclear area occupied by condensed chromatin and PG density $\left(\mathrm{PG} / \mu \mathrm{m}^{2}\right.$ of interchromatin space, i.e., the nucleoplasmic region devoid of condensed chromatin), area of the fibrillar centers, and percentage of the nucleolar area occupied by the dense fibrillar component and by the granular component.

To investigate the fine distribution of some RNA transcription and processing factors, thin muscle sections were treated with one of the following probes: mouse monoclonal antibodies directed against the activated, phosphorylated form of RNA polymerase II (Research Diagnostic Inc., Flanders, NJ) or against the snRNP (small nuclear RNP) Sm core proteins (Abcam, Cambridge, MA); rabbit polyclonal antibodies were used against DNA/RNA hybrid molecules [30] specifically occurring in the transcription sites [25, 31], and the cleavage stimulation factors CstF [32]. Sections were 
floated for 3 minutes on normal goat serum (NGS) diluted 1 : 100 in PBS and then incubated overnight at $4^{\circ} \mathrm{C}$ with the primary antibodies diluted with PBS containing $0.1 \%$ $(\mathrm{w} / \mathrm{v})$ bovine serum albumin (Fluka, Buchs, Switzerland) and $0.05 \%(\mathrm{v} / \mathrm{v})$ Tween 20. After rinsing, sections were floated on NGS, and then allowed to react for 20 minutes at room temperature with the secondary $12 \mathrm{~nm}$ or $18 \mathrm{~nm}-$ gold-conjugated antibody (Jackson ImmunoResearch Laboratories Inc., West Grove, PA) diluted 1:10 in PBS. Finally, the sections were rinsed and air-dried. As controls, some grids were incubated without the primary antibody and then processed as described above.

To reduce chromatin contrast and selectively reveal nuclear RNP constituents, the sections were bleached by the EDTA method [33], observed in a Philips Morgagni TEM operating at $80 \mathrm{kV}$, and equipped with a Megaview II camera for digital image acquisition.

Quantitative assessment of the immunolabeling was carried out by estimating the gold grain density over selected cellular compartments on sections treated in the same run. The surface area of the interchromatin space and IG was measured on fifteen satellite cell nuclei $(x 22,000)$ from each muscle by using a computerized image analysis system (AnalySIS Image processing). For background evaluation samples treated in the absence of primary antibody were considered. The gold grains over each selected compartment were counted, and the labeling density was expressed as the number of gold grains $/ \mu \mathrm{m}^{2}$.

2.4. Statistics. For each analyzed variable, the KolmogorovSmirnov two-sample test was performed in order to verify the hypothesis of identical distribution among animals of each experimental group (i.e., adult and old rats). The data were then pooled according to the experimental groups and the means \pm standard error of the mean (SE) values were calculated. Statistical comparisons were performed by the Mann Whitney $U$-test (significance was set at $P \leq 0.05$ ).

\section{Results}

As previously reported [25], a dramatic mass reduction was observed in both the biceps and quadriceps muscles of old rats in comparison to adult animals.

3.1. Light Microscopy. Satellite cells were specifically labeled by the anti-N-CAM antibody (Figure 1(a)); their density (number of satellite cells $/ 1000 \mu \mathrm{m}^{2}$ of muscle area) was significantly higher in adult than in old rats, in both the biceps and quadriceps muscle. Morphologically recognizable apoptotic nuclei in satellite cells of both muscles from adult rats were quite scarce; in muscles of old animals the percentage of apoptotic nuclei increased although not significantly (Figure 1(b)). It is, however, worth underlying that the absolute number of satellite apoptotic cells counted was very low, in both animal groups. Morphologically recognizable apoptotic nuclei in the myofibres were quite scarce and their percentage was similar in adult and old animals in both biceps $(0.16 \pm 0.06 \%$ versus $0.22 \pm 0.09$, resp. $)$ and quadriceps ( $0.15 \pm 0.06 \%$ versus $0.18 \pm 0.07$, resp.) muscles.
3.2. Transmission Electron Microscopy. In spite of the nonoptimal ultrastructural preservation due to the fixation procedure necessary for immunocytochemistry, in all the muscle samples satellite cells were morphologically recognizable as small cells with scanty cytoplasm and located between the sarcolemma and the surrounding basal lamina of the muscle fibers (Figure 2(a)). Satellite cell nuclei generally were ovoid in shape with finely irregular border and contained abundant condensed chromatin distributed both at the nuclear and nucleolar periphery, and one roundish compact nucleolus with prominent granular component, scarce dense fibrillar component, and rare small fibrillar centers (Figure 2(b)). In the nucleoplasm, all the usual RNP structural constituents involved in pre-mRNA transcription and processing were evident; few PF and PG were mainly distributed at the periphery of the condensed chromatin and small IG clusters occurred in the interchromatin space. In satellite cell nuclei of old muscles, PF sometimes occurred as clusters (Figures 2(d) and 2(h)). At electron microscopy, the satellite cell nuclei were structurally similar in adult and old rats, and morphological evidence of apoptosis was never found in any of the muscle samples examined.

In both biceps and quadriceps muscles, we did not observe significant differences between the satellite cells from adult and old rats as for the nuclear or nucleolar area, the percentage of condensed chromatin, the PG density, and the percentage of the dense fibrillar and the granular components of nucleoli (Figure 3). The area of the rare fibrillar centers observed ranged from 0.001 to $0.003 \mu \mathrm{m}^{2}$, without difference between muscles or age groups.

The immunocytochemical labeling for polymerase II, the DNA/RNA hybrid molecules, snRNPs, and the cleavage factor CstF were similar in the nucleoplasm of satellite cells from adult and old rats. In both animal groups, polymerase II and DNA/RNA hybrid molecules were exclusively associated with PF (Figures 2(c) and 2(d); snRNPs were restricted to PF and IG (Figures 2(e) and 2(f)); CstF was located essentially on PF and on RNP tails rising from PG (Figures $2(\mathrm{~g})$ and $2(\mathrm{~h})$ ).

The quantitative evaluation of the immunolabeling (Figure 4) revealed similar densities of polymerase II and DNA/RNA hybrid molecules in both biceps and quadriceps muscles of adult and old rats; conversely, snRNPs and CstF were more abundant in the interchromatin space of old rats compared to adult rats. In addition, snRNPs were found to be more abundant in the IG of old rats (biceps brachii: $16.12 \pm 2.86$ gold grains $/ \mu \mathrm{m}^{2}$ in adult versus $33.76 \pm 5.25$ in old rats, $P=0.047$; quadriceps femoris: $15.56 \pm 3.88$ gold grains $/ \mu \mathrm{m}^{2}$ in adult versus $34.97 \pm 5.94$ in old rats, $P=0.042$ ); conversely, in all the samples the labeling for polymerase II, the DNA/RNA hybrid molecules and CstF were almost absent on IG (Figures 2(c), 2(d), 2(g), and 2(h)). Background values were negligible in all immunolabeling experiments (not shown).

\section{Discussion}

The biceps brachii and the quadriceps femoris of the old rats were severely affected by sarcopenia, as demonstrated by the remarkable muscle mass reduction and the drastic decrease 

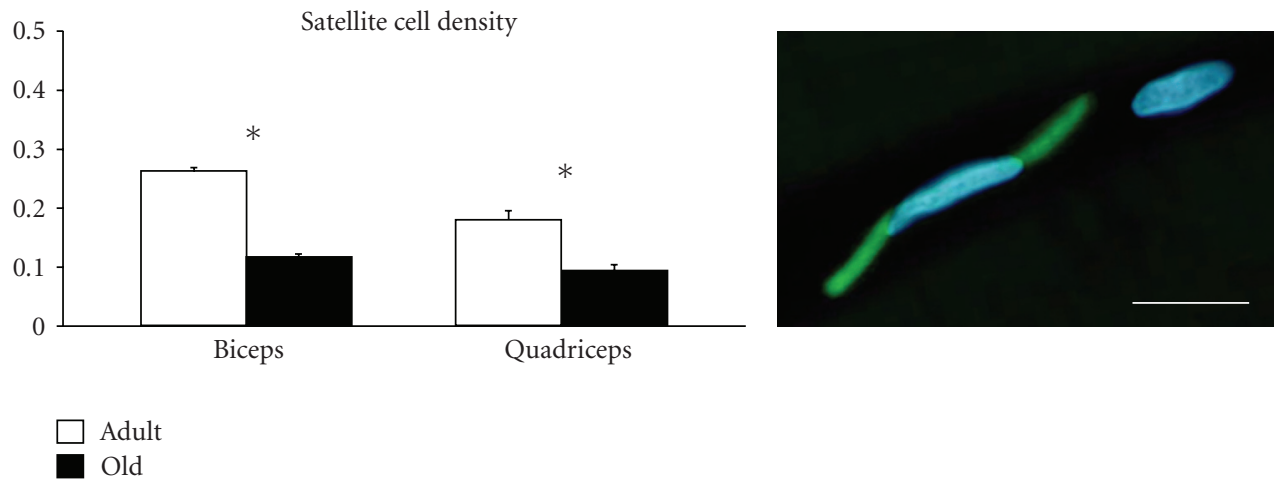

(a)

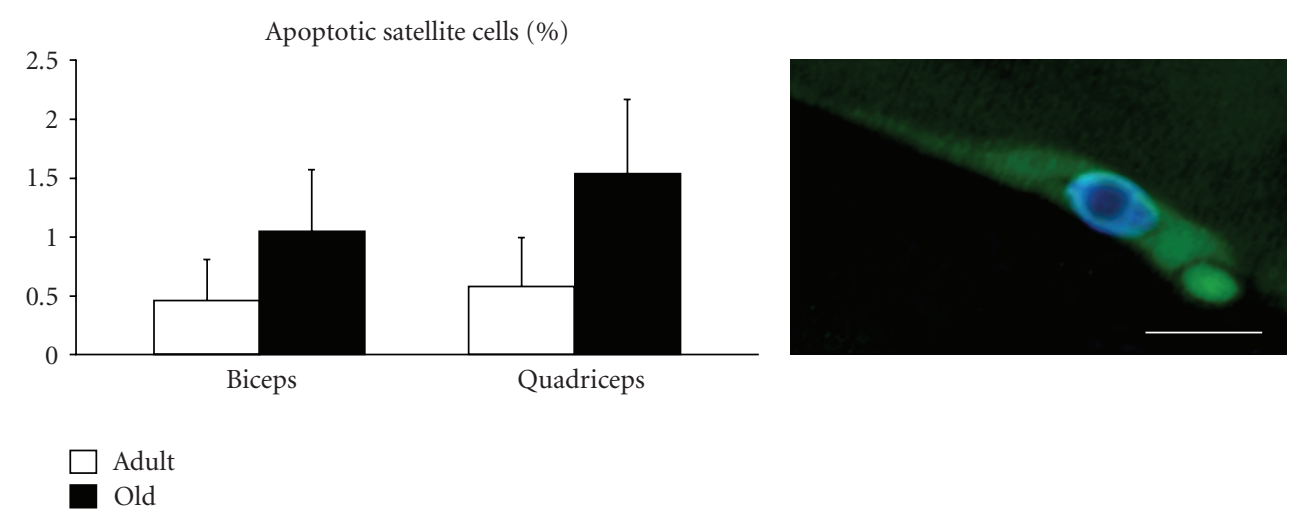

(b)

Figure 1: (a) Satellite cell density (number of satellite cells $/ 1000 \mu \mathrm{m}^{2}$ of muscle) in the biceps and quadriceps muscles of adult and old rats (mean $\pm \mathrm{SE}$ ). Asterisks show significantly different values $(P<0.001$ for both muscles). The inset shows a satellite cell labeled with the anti-N-CAM antibody (green fluorescence); DNA was stained with Hoechst 33258. Bar: $10 \mu \mathrm{m}$. (b) Percentage of apoptotic satellite cells in the biceps and quadriceps muscles of adult and old rats (mean $\pm \mathrm{SE})$. The values were not significantly different $(P=0.136$ for biceps and $P=0.157$ for quadriceps). The inset shows an apoptotic satellite cell (green fluorescence); DNA was stained with Hoechst 33258 , note the marginated chromatin. Bar: $10 \mu \mathrm{m}$.

in the size of type II myofiber [25]. The density of satellite cells was also significantly decreased in old rats compared to adult rats, consistent with the impaired regenerative capacity of muscles in sarcopenia. A smaller amount of satellite cells has already been reported in different aging muscles (e.g., [4-8]), although some authors did not observe these quantitative changes [11-13]. This discrepancy could be due to the differences in muscle, myofiber, and atrophy types that were investigated (for a recent review, see [34]); in particular, it has been reported that satellite cell content is specifically reduced in type II skeletal muscle fibers in the elderly [8], thus making muscles, which are mainly composed of this fiber type (like the biceps brachii and the quadriceps femoris), especially prone to satellite cell loss.

The scarce presence of morphologically recognizable apoptotic nuclei in satellite cells (at both light and electron microscopy) suggests that cell death via apoptosis might rarely occur in aging skeletal muscles. However, it should be also considered that our data have been collected in old animals where the sarcopenic process had already come to an advanced stage; this implies that a substantial role of apoptosis in earlier phases cannot be excluded. In any case, in both muscles of old rats the percentage of apoptotic satellite cell nuclei was increased (thought not significantly); whereas apoptotic nuclei were rare in myofibers, without differences between adult and old animals [25, 35]; these findings support the hypothesis that the apoptotic signals in old muscles may mostly originate from satellite cells [36].

The satellite cells bordering the myofibers of old muscles are morphologically similar to those found in adult muscles; in particular, the structural features of their nuclei are typical of quiescent cells. They contain abundant clumps of condensed chromatin, few PF and PG [22], compact nucleoli with abundant granular components, and scarce dense fibrillar components [37], which are all markers of low nuclear activity. Accordingly, the quantitative evaluation of the fine structural features of satellite cell nuclei gave similar values in adult and old rats; however, the in situ analysis of pre-mRNA processing factors revealed significant differences in the amount and intranuclear distribution of snRNPs and CstF. In detail, the snRNPs (involved in the cotranscriptional splicing of pre-mRNA [38]) were found to increase in satellite cell nuclei of old muscles; however, analysis of their intranuclear distribution reveals that snRNPs accumulate in 


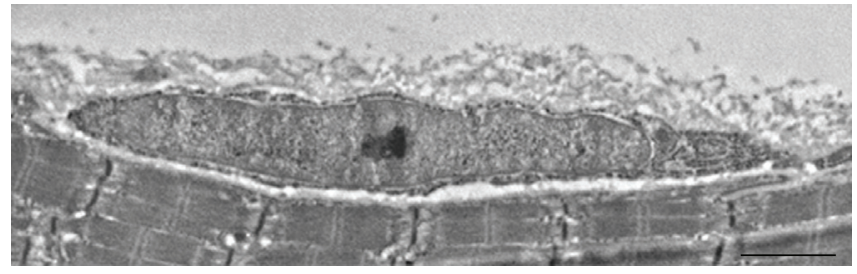

(a)

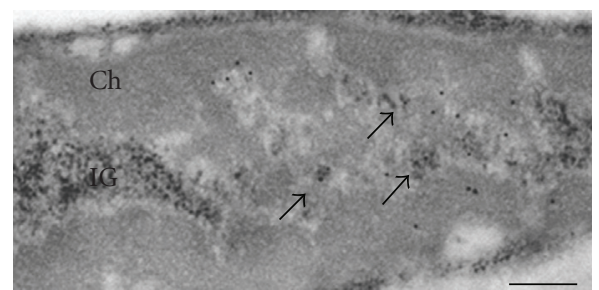

(c)

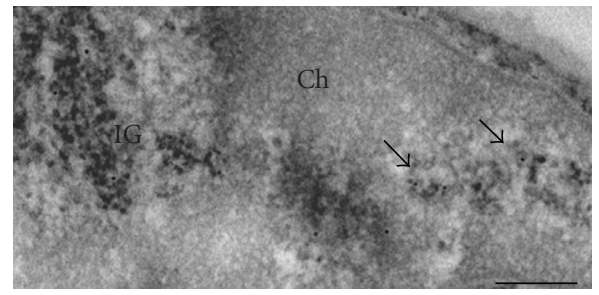

(e)

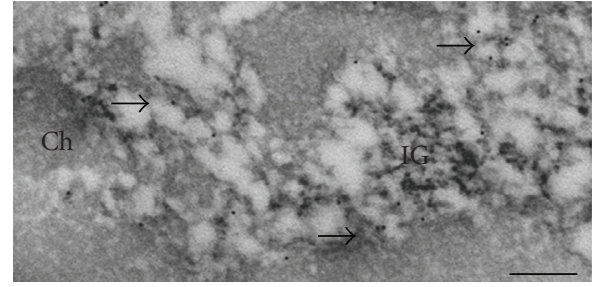

(g)

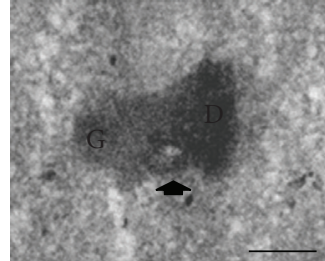

(b)

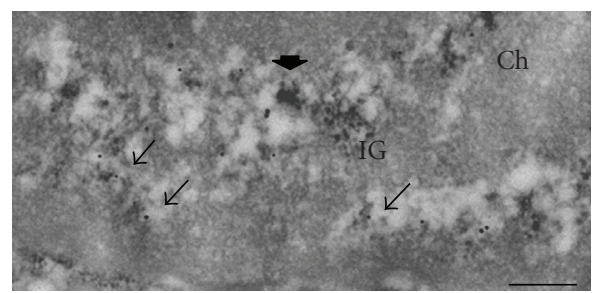

(d)

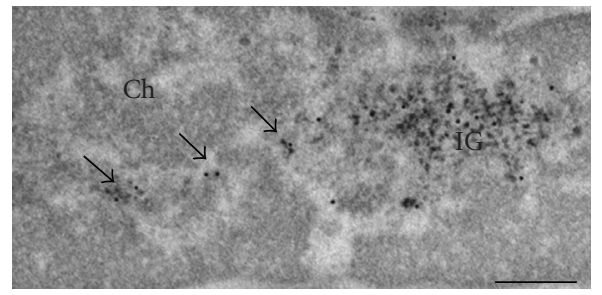

(f)

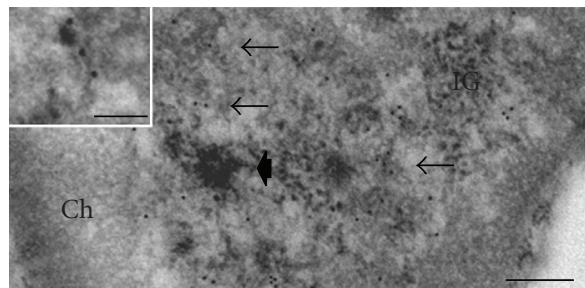

(h)

FIgURE 2: Transmission electron micrographs. (a) Satellite cell bordering a myofiber. (b) Detail showing the nucleolus mostly composed of granular component $(\mathrm{G})$; whereas the dense fibrillar component $(\mathrm{D})$ is less abundant, note the small fibrillar center (arrowhead). Satellite cell nuclei from adult ( $c$, e and g) and old ( $\mathrm{d}, \mathrm{f}$ and $\mathrm{h}$ ) rats. ( $\mathrm{c}$ and $\mathrm{d}$ ) Quadriceps muscles, anti-polymerase II (12 nm), and anti-DNA/RNA hybrid $(18 \mathrm{~nm})$ antibodies: both antibody probes specifically label perichromatin fibrils (arrows). Note the clustered perichromatin fibrils in (d) (arrowhead). The interchromatin granules (IG) are unlabeled. (e, f) Biceps muscles, anti-snRNP antibody: perichromatin fibrils (arrows) and interchromatin granules (IG) are labeled. (g, h) Quadriceps muscles, anti-CstF antibody: gold grains specifically label perichromatin fibrils (arrows) and RNP tails rising from perichromatin granules (inset). Note the cluster of perichromatin fibrils in (h) (arrowhead). Interchromatin granules (IGs) are unlabeled. Ch: condensed chromatin. Bars: (a) $1 \mu \mathrm{m}$; (b-h) $250 \mathrm{~nm}$; inset $100 \mathrm{~nm}$.

the IG, known to represent the site of storage, transit and recycling of many nuclear factors $[24,39]$, but not on PF, which represent the in situ form of nascent transcripts, as well as of their splicing and $3^{\prime}$ end processing (reviews in $[22,23])$. Therefore, the increase in snRNPs is not associated with an increase in the transcriptional rate, according to the results obtained for polymerase II and the DNA/RNA hybrid molecules. A similar accumulation of nuclear factors in IG has been previously described in hepatocytes and neurons of old rodents [19-21], suggesting that the RNA pathways impairment may represent a common event during aging, independently on the cell type. The cleavage factor CstF also increases in satellite cell nuclei of old muscles in comparison to the adult ones; however, this factor was always and exclusively located on PF. A similar accumulation of CstF has been previously observed in myonuclei of old muscles [25] as well as in aging hepatocyte nuclei [21]. Consistent with the data on snRNPs, the accumulation of CstF suggests that the processing and/or the intranuclear transport of transcripts are impaired. The presence of clustered PF as well as the increase in PG density observed in satellite cell nuclei of old muscles (although below the level of statistical significance) supports the hypothesis of altered pre-mRNA cotranscriptional activities and reduced cytoplasmic export. In fact, PF (which represent sensitive markers for the premRNA processing impairment [23]) have been already 


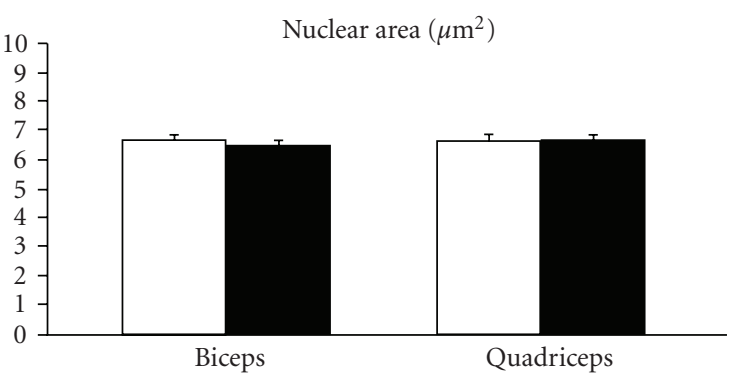

(a)

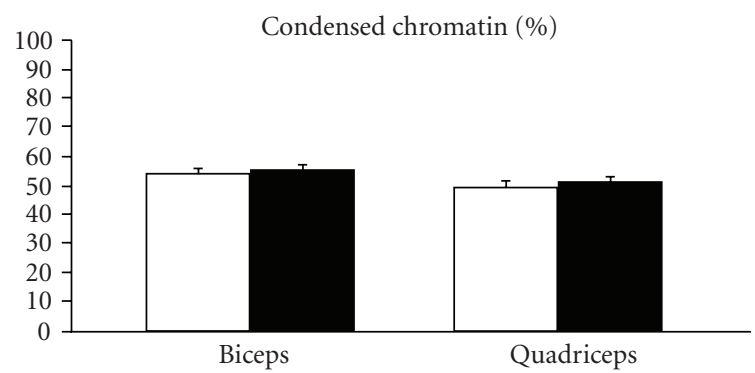

(c)

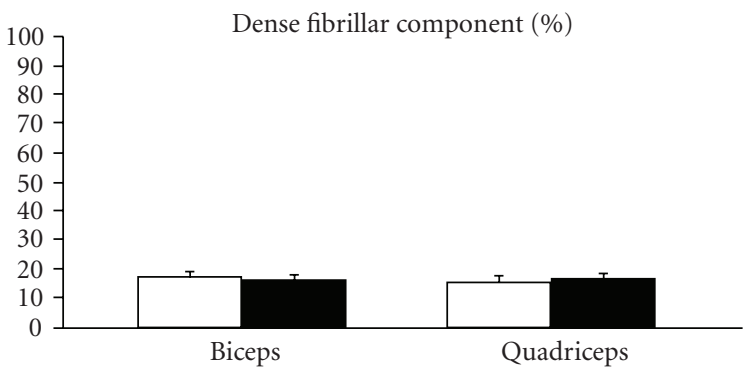

$\square$ Adult

Old

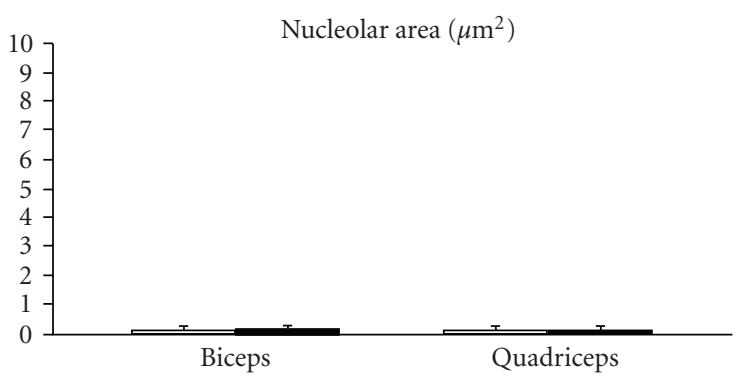

(b)

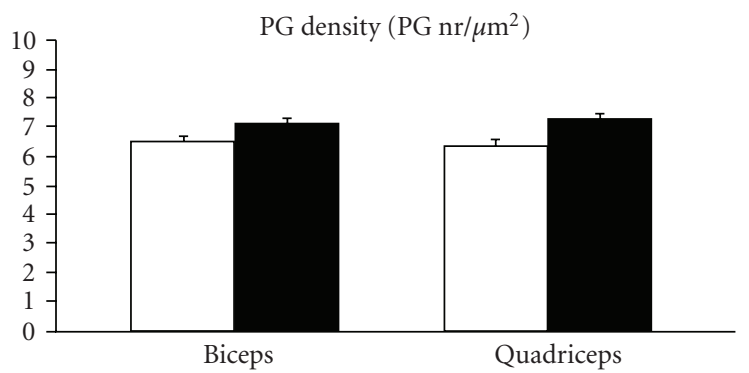

(d)

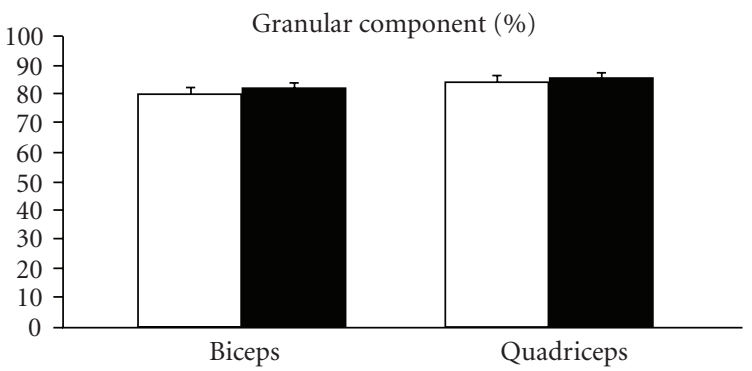

Adult

Old

(e)

(f)

FIGURE 3: Morphometrical parameters measured on electron micrographs of satellite cell nuclei from the biceps and quadriceps muscles of adult and old rats (mean $\pm \mathrm{SE}$ ). No significant difference was found between the two ages.

observed to accumulate in aging hepatocytes $[17,21]$; moreover, PG (which represent storage and/or transport sites for spliced (pre-)mRNA [22]) generally increase in number as a consequence of altered pre-mRNA processing as well as of impaired intranuclear or nucleus-to-cytoplasm transport of mRNAs (e.g., [40, 41]). Consistent with this hypothesis, a decrease in the nucleus-to-cytoplasm transport factors [42] has been reported during aging, when the degradation systems also undergo alterations [43] leading to the accumulation of cross-linked, insoluble, and often oxidized proteins, which may damage the intracellular transport mechanisms $[44,45]$. Accordingly, several proteins have been found to accumulate in satellite cell nuclei of old skeletal muscles [46]. In this view, the intranuclear accumulation of some nuclear factors in aging cell nuclei could be also related to the reduced efficacy of their degradation machinery. It is worth noting that the abnormal accumulation of reactive oxygen species in skeletal myofibers and satellite cells $[47,48]$ as well as dysfunctions in the proteolytic and autophagic pathways $[49,50]$ is thought to be involved in sarcopenia.

Interestingly, when the results obtained for satellite cells are compared to those recently reported for myonuclei of the same muscles [25], it appears that satellite cell nuclei are less affected by aging: myonuclei show alterations in their fine structural and molecular features indicating that the entire mRNA production chain, from the synthesis to the cytoplasmic export, becomes less efficient; whereas in satellite cell nuclei the pre-mRNA processing/transport only is affected. This could be due to the relatively low nuclear activity of satellite cells, compared to myonuclei, which could in turn results in the slowing down of the progressive agerelated deterioration of the whole cell function, including the RNA production [43]. The changes in the mRNA production machinery revealed in this study, however, suggest that satellite cell nuclei of aged individuals might be less responsive to the activating stimuli that those in adults, 


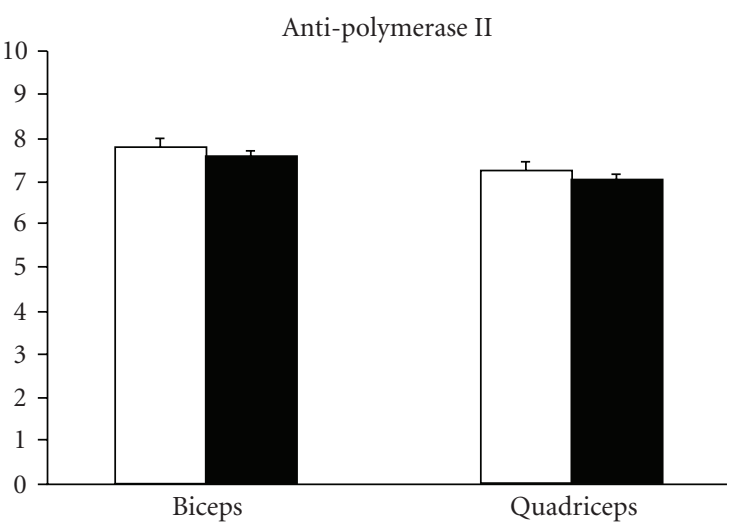

(a)

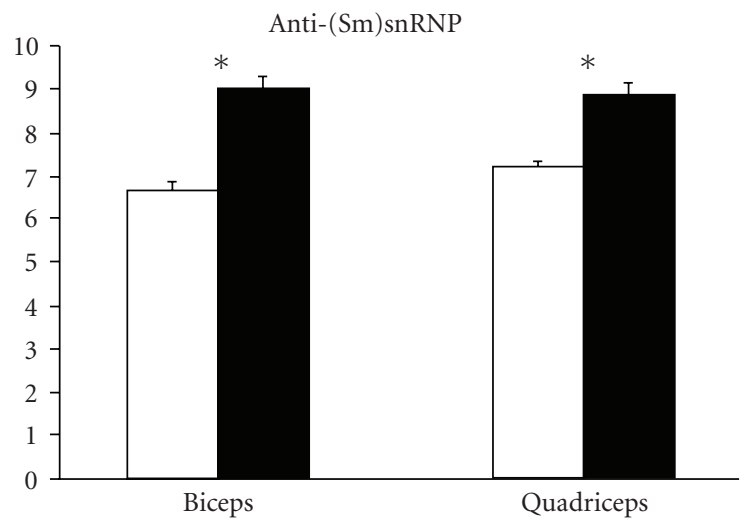

$\square$ Adult

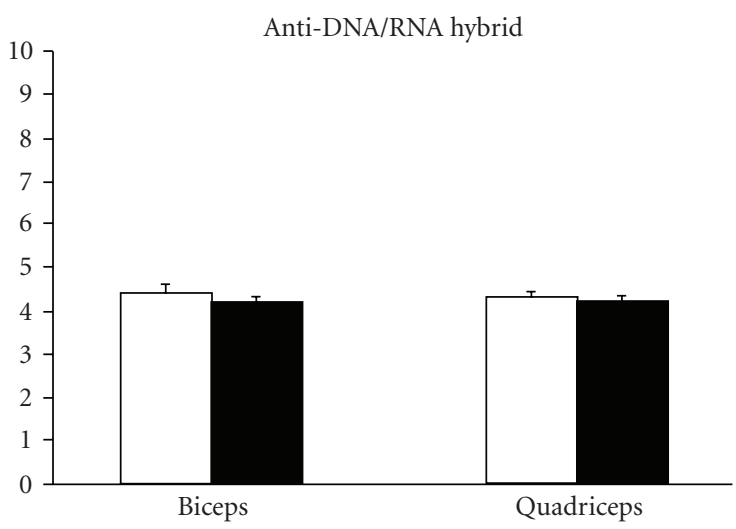

(b)

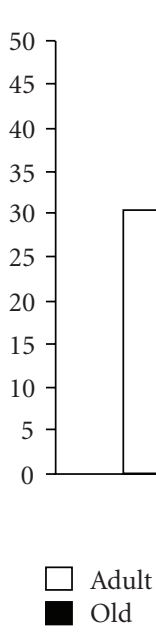

Anti-CstF

(c)

(d)

FIGURE 4: Quantitative immunoelectron microscopy of satellite cell nuclei of biceps and quadriceps muscles from adult and old rats; labeling density (gold grains $/ \mu \mathrm{m}^{2}$ ) of some RNA processing factors in the interchromatin space (mean \pm SE). Asterisks show significantly different values.

thus compromising the regenerative capacity of old skeletal muscles.

\section{Conclusions}

There is growing evidence in the literature that aging affects cell nuclear function by impairing the transcriptional/cotranscriptional mechanisms in a wide variety of cell types in different organs, including muscles; this leads to a number of metabolic consequences, which finally result in the impairment of the specific physiological role(s) of each cell type. Recently, it has been demonstrated that defects in the RNA pathways are paralleled by altered intranuclear distribution of pre-mRNAs processing factors in some diseases characterized by muscle atrophy/dystrophy [51-53]. It is likely that the age-related nuclear dysfunctions of satellite cells could hamper their capability to become activated and to proliferate in response to muscle damage.

Thus nuclear dysfunction of both muscle fibers and satellite cells seems to play a pivotal role in the sarcopenia of aged individuals, and this should be taken into account in the perspective to prevent and treat this ever-increasing health-risk factor.

\section{Acknowledgment}

F. Perdoni is a Ph.D. student in receipt of a fellowship from the Dottorato di Ricerca in Biologia Cellulare (University of Pavia).

\section{References}

[1] T. Lang, T. Streeper, P. Cawthon, K. Baldwin, D. R. Taaffe, and T. B. Harris, "Sarcopenia: etiology, clinical consequences, intervention, and assessment," Osteoporosis International, pp. $1-17,2009$.

[2] J. G. Ryall, J. D. Schertzer, and G. S. Lynch, "Cellular and molecular mechanisms underlying age-related skeletal muscle wasting and weakness," Biogerontology, vol. 9, no. 4, pp. 213228,2008

[3] L. V. Thompson, "Age-related muscle dysfunction," Experimental Gerontology, vol. 44, no. 1-2, pp. 106-111, 2009. 
[4] M. C. Gibson and E. Schultz, "Age-related differences in absolute numbers of skeletal muscle satellite cells," Muscle \& Nerve, vol. 6, no. 8, pp. 574-580, 1983.

[5] V. Renault, E. Rolland, L. E. Thornell, V. Mouly, and G. ButlerBrowne, "Distribution of satellite cells in the human vastus lateralis muscle during aging," Experimental Gerontology, vol. 37, no. 12, pp. 1513-1514, 2002.

[6] F. Kadi, N. Charifi, C. Denis, and J. Lexell, "Satellite cells and myonuclei in young and elderly women and men," Muscle \& Nerve, vol. 29, no. 1, pp. 120-127, 2004.

[7] A. S. Brack, H. Bildsoe, and S. M. Hughes, "Evidence that satellite cell decrement contributes to preferential decline in nuclear number from large fibres during murine age-related muscle atrophy," Journal of Cell Science, vol. 118, no. 20, pp. 4813-4821, 2005.

[8] L. B. Verdijk, R. Koopman, G. Schaart, K. Meijer, H. H. C. M. Savelberg, and L. J. C. van Loon, "Satellite cell content is specifically reduced in type II skeletal muscle fibers in the elderly," American Journal of Physiology, vol. 292, no. 1, pp. E151-E157, 2007.

[9] S. S. Jejurikar, E. A. Henkelman, P. S. Cederna, C. L. Marcelo, M. G. Urbanchek, and W. M. Kuzon Jr., "Aging increases the susceptibility of skeletal muscle derived satellite cells to apoptosis," Experimental Gerontology, vol. 41, no. 9, pp. 828836, 2006.

[10] S. E. Alway and P. M. Siu, "Nuclear apoptosis contributes to sarcopenia," Exercise and Sport Sciences Reviews, vol. 36, no. 2, pp. 51-57, 2008.

[11] S. M. Roth, G. F. Martel, F. M. Ivey, et al., "Skeletal muscle satellite cell populations in healthy young and older men and women," Anatomical Record, vol. 260, no. 4, pp. 351-358, 2000.

[12] R. Schafer, M. Zweyer, U. Knauf, R. R. Mundegar, and A. Wernig, "The ontogeny of soleus muscles in $\mathrm{mdx}$ and wild type mice," Neuromuscular Disorders, vol. 15, no. 1, pp. 57-64, 2005.

[13] N. E. Brooks, M. D. Schuenke, and R. S. Hikida, "No change in skeletal muscle satellite cells in young and aging rat soleus muscle," The Journal of Physiological Sciences, vol. 59, no. 6, pp. 465-471, 2009.

[14] E. Schultz and B. H. Lipton, "Skeletal muscle satellite cells: changes in proliferation potential as a function of age," Mechanisms of Ageing and Development, vol. 20, no. 4, pp. 377383, 1982.

[15] S. Machida and M. Narusawa, "The roles of satellite cells and hematopoietic stem cells in impaired regeneration of skeletal muscle in old rats," Annals of the New York Academy of Sciences, vol. 1067, no. 1, pp. 349-353, 2006.

[16] E. Meshorer and H. Soreq, "Pre-mRNA splicing modulations in senescence," Aging Cell, vol. 1, no. 1, pp. 10-16, 2002.

[17] M. Malatesta, C. Bertoni-Freddari, P. Fattoretti, C. Caporaloni, S. Fakan, and G. Gazzanelli, "Altered RNA structural constituents in aging and vitamin E deficiency," Mechanisms of Ageing and Development, vol. 124, no. 2, pp. 175-181, 2003.

[18] M. Malatesta, C. Bertoni-Freddari, P. Fattoretti, B. Baldelli, S. Fakan, and G. Gazzanelli, "Aging and vitamin E deficiency are responsible for altered RNA pathways," Annals of the New York Academy of Sciences, vol. 1019, pp. 379-382, 2004.

[19] M. Malatesta, B. Baldelli, S. Battistelli, P. Fattoretti, and C. Bertoni-Freddari, "Aging affects the distribution of the circadian CLOCK protein in rat hepatocytes," Microscopy Research and Technique, vol. 68, no. 1, pp. 45-50, 2005.
[20] M. Malatesta, P. Fattoretti, B. Baldelli, S. Battistelli, M. Balietti, and C. Bertoni-Freddari, "Effects of ageing on the fine distribution of the circadian CLOCK protein in reticular formation neurons," Histochemistry and Cell Biology, vol. 127, no. 6, pp. 641-647, 2007.

[21] M. Malatesta, M. Biggiogera, B. Cisterna, M. Balietti, C. Bertoni-Freddari, and P. Fattoretti, "Perichromatin fibrils accumulation in hepatocyte nuclei reveals alterations of premRNA processing during ageing," DNA and Cell Biology, vol. 29, no. 2, pp. 49-57, 2010.

[22] S. Fakan, "Ultrastructural cytochemical analyses of nuclear functional architecture," European Journal of Histochemistry, vol. 48, no. 1, pp. 5-14, 2004.

[23] M. Biggiogera, B. Cisterna, A. Spedito, L. Vecchio, and M. Malatesta, "Perichromatin fibrils as early markers of transcriptional alterations," Differentiation, vol. 76, no. 1, pp. 57-65, 2008.

[24] D. Bogolyubov, I. Stepanova, and V. Parfenov, "Universal nuclear domains of somatic and germ cells: some lessons from oocyte interchromatin granule cluster and Cajal body structure and molecular composition," BioEssays, vol. 31, no. 4, pp. 400-409, 2009.

[25] M. Malatesta, F. Perdoni, S. Muller, C. Zancanaro, and C. Pellicciari, "Nuclei of aged myofibres undergo structural and functional changes suggesting impairment in RNA processing," European Journal of Histochemistry, vol. 53, no. 2, pp. 97106, 2009.

[26] L. Larsson, B. Sjodin, and J. Karlsson, "Histochemical and biochemical changes in human skeletal muscle with age in sedentary males, age 22-65 yrs," Acta Physiologica Scandinavica, vol. 103, no. 1, pp. 31-39, 1978.

[27] J. Lexell, "Human aging, muscle mass, and fiber type composition," The Journals of Gerontology. Series A, vol. 50, pp. 11-16, 1995.

[28] C. D. Shorey, L. A. Manning, and A. V. Everitt, "Morphometrical analysis of skeletal muscle fibre ageing and the effect of hypophysectomy and food restriction in the rat," Gerontology, vol. 34, no. 3, pp. 97-109, 1988.

[29] J. Covault, J. P. Merlie, C. Goridis, and J. R. Sanes, "Molecular forms of N-CAM and its RNA in developing and denervated skeletal muscle," The Journal of Cell Biology, vol. 102, no. 3, pp. 731-739, 1986.

[30] P. S. Testillano, E. Gorab, and M. C. Risueno, "A new approach to map transcription sites at the ultrastructural level," Journal of Histochemistry and Cytochemistry, vol. 42, no. 1, pp. 1-10, 1994.

[31] M. Malatesta, F. Perdoni, S. Battistelli, S. Muller, and C. Zancanaro, "The cell nuclei of skeletal muscle cells are transcriptionally active in hibernating edible dormice," BMC Cell Biology, vol. 10, article 19, 2009.

[32] K. L. Veraldi, G. K. Arhin, K. Martincic, L.-H. Chung-Ganster, J. Wilusz, and C. Milcarek, "hnRNP F influences binding of a 64-kilodalton subunit of cleavage stimulation factor to mRNA precursors in mouse B cells," Molecular and Cellular Biology, vol. 21, no. 4, pp. 1228-1238, 2001.

[33] W. Bernhard, "A new staining procedure for electron microscopical cytology," Journal of Ultrasructure Research, vol. 27, no. 3-4, pp. 250-265, 1969.

[34] N. E. Brooks, M. D. Schuenke, and R. S. Hikida, "Ageing influences myonuclear domain size differently in fast and slow skeletal muscle of rats," Acta Physiologica, vol. 197, no. 1, pp. 55-63, 2009. 
[35] C. Zancanaro, R. Mariotti, F. Perdoni, E. Nicolato, and M. Malatesta, "Physical training is associated with changes in nuclear magnetic resonance and morphometrical parameters of the skeletal muscle in senescent mice," European Journal of Histochemistry, vol. 51, no. 4, pp. 305-309, 2007.

[36] K. Gundersen and J. C. Bruusgaard, "Nuclear domains during muscle atrophy: nuclei lost or paradigm lost?" Journal of Physiology, vol. 586, no. 11, pp. 2675-2681, 2008.

[37] H. G. Schwarzacher and F. Wachtler, "The nucleolus," Anatomy and Embryology, vol. 188, no. 6, pp. 515-536, 1993.

[38] R. Lührmann, B. Kastner, and M. Bach, "Structure of spliceosomal snRNPs and their role in pre-mRNA splicing," Biochimica et Biophysica Acta, vol. 1087, no. 3, pp. 265-292, 1990.

[39] E. Puvion and F. Puvion-Dutilleul, "Ultrastructure of the nucleus in relation to transcription and splicing: roles of perichromatin fibrils and interchromatin granules," Experimental Cell Research, vol. 229, no. 2, pp. 217-225, 1996.

[40] F. Puvion-Dutilleul and E. Puvion, "Relationship between chromatin and perichromatin granules in cadmium-treated isolated hepatocytes," Journal of Ultrastructure Research, vol. 74, no. 3, pp. 341-350, 1981.

[41] C. Zancanaro, M. Malatesta, P. Vogel, F. Osculati, and S. Fakan, "Ultrastructural and morphometrical analyses of the brown adipocyte nucleus in a hibernating dormouse," Biology of the Cell, vol. 79, no. 1, pp. 55-61, 1993.

[42] G. Pujol, H. Soderqvist, and A. Radu, "Age-associated reduction of nuclear protein import in human fibroblasts," Biochemical and Biophysical Research Communications, vol. 294, no. 2, pp. 354-358, 2002.

[43] C. W. Jameson, “Towards a unified and interdiciplinary model of ageing," Medical Hypotheses, vol. 63, no. 1, pp. 83-86, 2004.

[44] A. Hallen, "Accumulation of insoluble protein and aging," Biogerontology, vol. 3, no. 5, pp. 307-315, 2002.

[45] J. H. Kim, H. E. Choy, K. H. Nam, and S. C. Park, "Transglutaminase-mediated crosslinking of specific core histone subunits and cellular senescence," Annals of the New York Academy of Sciences, vol. 928, pp. 65-70, 2001.

[46] S. Machida and F. W. Booth, "Increased nuclear proteins in muscle satellite cells in aged animals as compared to young growing animals," Experimental Gerontology, vol. 39, no. 10, pp. 1521-1525, 2004.

[47] S. Fulle, F. Protasi, G. Di Tano, et al., "The contribution of reactive oxygen species to sarcopenia and muscle ageing," Experimental Gerontology, vol. 39, no. 1, pp. 17-24, 2004.

[48] S. Fulle, S. Di Donna, C. Puglielli, et al., "Age-dependent imbalance of the antioxidative system in human satellite cells," Experimental Gerontology, vol. 40, no. 3, pp. 189-197, 2005.

[49] D. Attaix, L. Mosoni, D. Dardevet, L. Combaret, P. P. Mirand, and J. Grizard, "Altered responses in skeletal muscle protein turnover during aging in anabolic and catabolic periods," The International Journal of Biochemistry \& Cell Biology, vol. 37, no. 10, pp. 1962-1973, 2005.

[50] L. Combaret, D. Dardevet, D. Béchet, D. Taillandier, L. Mosoni, and D. Attaix, "Skeletal muscle proteolysis in aging," Current Opinion in Clinical Nutrition and Metabolic Care, vol. 12, no. 1, pp. 37-41, 2009.

[51] R. Cardani, E. Mancinelli, G. Rotondo, V. Sansone, and G. Meola, "Muscleblind-like protein 1 nuclear sequestration is a molecular pathology marker of DM1 and DM2," European Journal of Histochemistry, vol. 50, no. 3, pp. 177-182, 2006.
[52] T. M. Wheeler and C. A. Thornton, "Myotonic dystrophy: RNA-mediated muscle disease," Current Opinion in Neurology, vol. 20, no. 5, pp. 572-576, 2007.

[53] F. Perdoni, M. Malatesta, R. Cardani, et al., "RNA/MBNL1containing foci in myoblast nuclei from patients affected by myotonic dystrophy type 2: an immunocytochemical study," European Journal of Histochemistry, vol. 53, no. 3, pp. 151-158, 2009. 

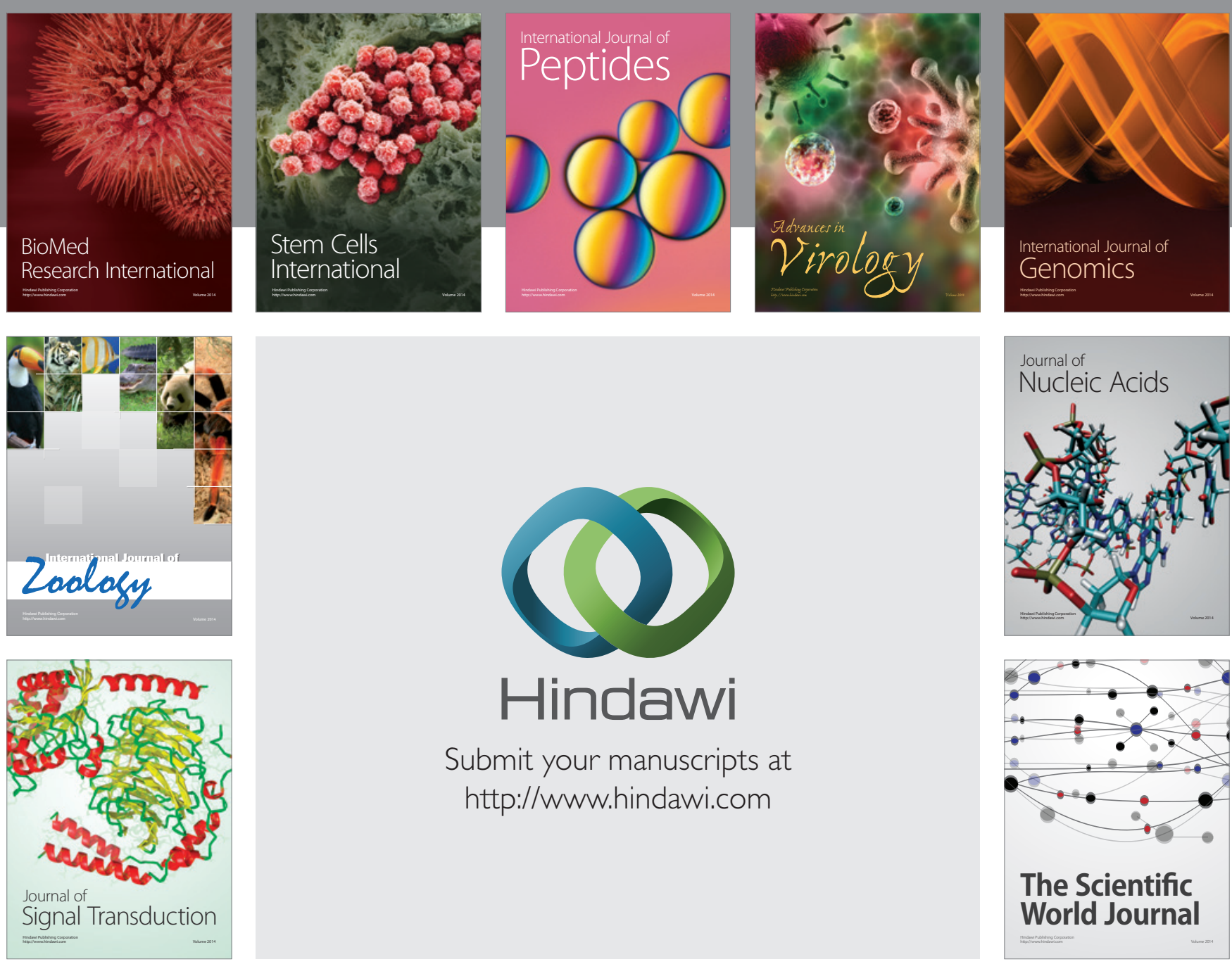

Submit your manuscripts at

http://www.hindawi.com
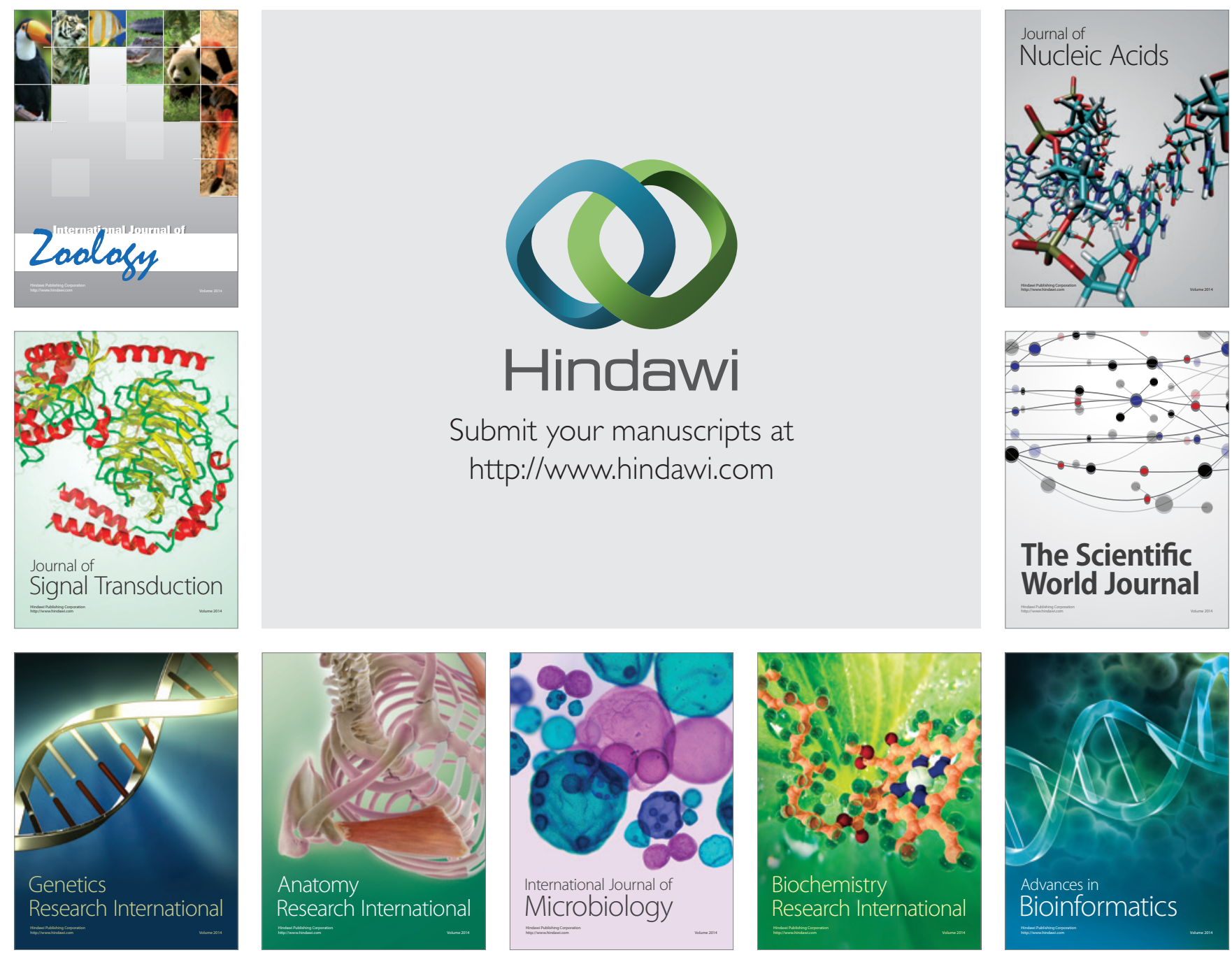

The Scientific World Journal
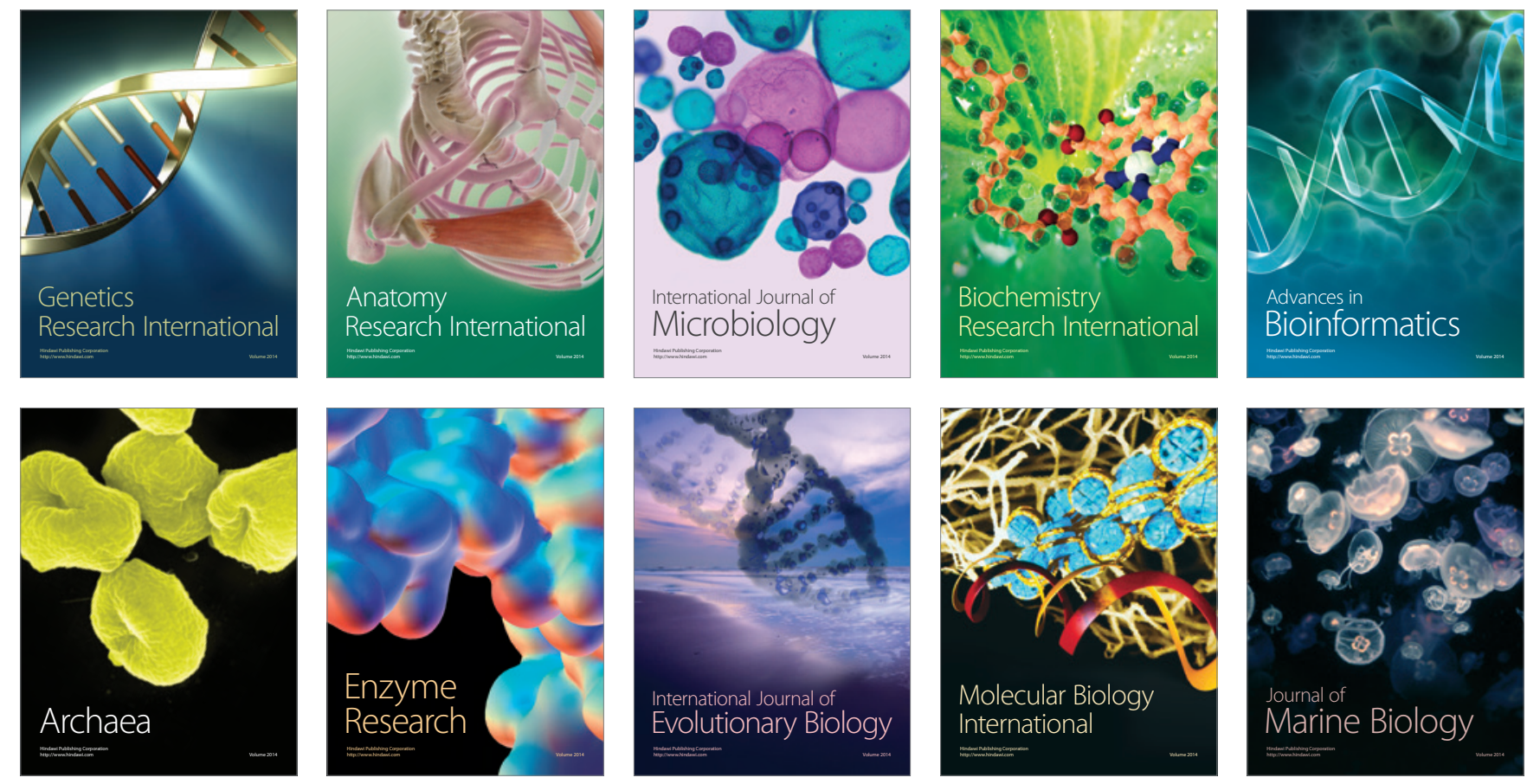